\title{
Front Matter: Volume 7713
}

, "Front Matter: Volume 7713," Proc. SPIE 7713, Photonic Crystal Materials and Devices IX, 771301 (3 June 2010); doi: 10.1117/12.868173

SPIE. Event: SPIE Photonics Europe, 2010, Brussels, Belgium 


\title{
PROCEEDINGS OF SPIE
}

\section{Photonic Crystal Materials and Devices IX}

\author{
Hernán R. Míguez \\ Sergei G. Romanov \\ Lucio Claudio Andreani \\ Christian Seassal \\ Editors
}

\section{2-15 April 2010 \\ Brussels, Belgium}

Sponsored by

SPIE

Cosponsored By

B-PHOT—Brussels Photonics Team (Belgium) - Brussels-Capital Region (Belgium) • FWO-Fonds Wetenschappelijk Onderzoek (Belgium) • ICO_International Commission for Optics • Ville de Bruxelles (Belgium)

Cooperating Organisations

CBO-BCO (Belgium) • EOS-European Optical Society (Germany) • IET— The Institution of Engineering and Technology (United Kingdom) $\bullet$ IOP-Institute of Physics (United Kingdom) Photonics4Life (Germany) - Photonics@be (Belgium) • Photonics 21 (Germany) • PromOptica (Belgium)

Published by

SPIE

Volume 7713 
The papers included in this volume were part of the technical conference cited on the cover and title page. Papers were selected and subject to review by the editors and conference program committee. Some conference presentations may not be available for publication. The papers published in these proceedings reflect the work and thoughts of the authors and are published herein as submitted. The publisher is not responsible for the validity of the information or for any outcomes resulting from reliance thereon.

Please use the following format to cite material from this book:

Author(s), "Title of Paper," in Photonic Crystal Materials and Devices IX, edited by Hernán R. Míguez, Sergei G. Romanov, Lucio Claudio Andreani, Christian Seassal, Proceedings of SPIE Vol. 7713 (SPIE, Bellingham, WA, 2010) Article CID Number.

ISSN 0277-786X

ISBN 9780819481863

Published by

SPIE

P.O. Box 10, Bellingham, Washington 98227-0010 USA

Telephone +1 3606763290 (Pacific Time) · Fax +1 3606471445

SPIE.org

Copyright (C) 2010, Society of Photo-Optical Instrumentation Engineers

Copying of material in this book for internal or personal use, or for the internal or personal use of specific clients, beyond the fair use provisions granted by the U.S. Copyright Law is authorized by SPIE subject to payment of copying fees. The Transactional Reporting Service base fee for this volume is $\$ 18.00$ per article (or portion thereof), which should be paid directly to the Copyright Clearance Center (CCC), 222 Rosewood Drive, Danvers, MA 01923. Payment may also be made electronically through CCC Online at copyright.com. Other copying for republication, resale, advertising or promotion, or any form of systematic or multiple reproduction of any material in this book is prohibited except with permission in writing from the publisher. The CCC fee code is 0277-786X/10/\$18.00.

Printed in the United States of America.

Publication of record for individual papers is online in the SPIE Digital Library.

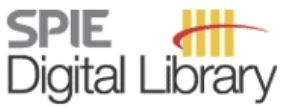

SPIEDigitalLibrary.org

Paper Numbering: Proceedings of SPIE follow an e-First publication model, with papers published first online and then in print and on CD-ROM. Papers are published as they are submitted and meet publication criteria. A unique, consistent, permanent citation identifier (CID) number is assigned to each article at the time of the first publication. Utilization of CIDs allows articles to be fully citable as soon they are published online, and connects the same identifier to all online, print, and electronic versions of the publication. SPIE uses a six-digit CID article numbering system in which:

- The first four digits correspond to the SPIE volume number.

- The last two digits indicate publication order within the volume using a Base 36 numbering system employing both numerals and letters. These two-number sets start with 00, 01, 02, 03, 04, $05,06,07,08,09,0 A, 0 B \ldots 0 Z$, followed by 10-1Z, 20-2Z, etc.

The CID number appears on each page of the manuscript. The complete citation is used on the first page, and an abbreviated version on subsequent pages. Numbers in the index correspond to the last two digits of the six-digit CID number. 


\section{Contents}

ix Conference Committee

xiii Introduction

SESSION 1 RECENT ADVANCES IN THE PREPARATION AND CHARACTERISATOIN OF SELF-ASSEMBLED PHOTONIC CRYSTALS

771302 Light scattering in opal-based photonic crystals (Invited Paper) [7713-01]

M. F. Limonov, loffe Physical-Technical Institute (Russian Federation)

771303 Toward a full understanding of the growth dynamics, optical response, and crystalline structure of self-assembled photonic colloidal crystal films [7713-02]

G. Lozano, Instituto de Ciencia de Materiales de Sevilla (Spain); L. A. Dorado, R. A. Depine, Univ. de Buenos Aires (Argentina); H. R. Míguez, Instituto de Ciencia de Materiales de Sevilla (CSIC-US) (Spain)

771304 Polarization anisotropy and cross-polarized transmission in thin film opal-based photonic crystals [7713-03]

S. G. Romanov, Univ. Erlangen-Nürnberg (Germany) and loffe Physical Technical Institute (Russian Federation); U. Peschel, Univ. Erlangen-Nürnberg (Germany); W. Khunsin,

Max-Planck-Institut für Festkörperforschung (Germany); S. Essig, K. Busch, Karlsruhe Institute of Technology (Germany)

771306 Molding resonant energy transfer by colloidal crystal: Dexter transfer and electroluminescence [7713-05]

L. González-Urbina, Katholieke Univ. Leuven (Belgium); B. Kolaric, Univ. de Mons (Belgium);

W. Libaers, K. Clays, Katholieke Univ. Leuven (Belgium)

\section{SESSION 2 LIGHT MANAGING IN PHOTOVOLTAIC AND LIGHT-EMITTING DEVICES USING PHOTONIC} CRYSTALS

771307 Enhancement of solar cell efficiency using two-dimensional photonic crystals (Invited Paper) [7713-06]

P. A. Postigo, M. Kaldirim, I. Prieto, L. J. Martínez, M. L. Dotor, Instituto de Microelectrónica de Madrid (Spain); M. Galli, L. C. Andreani, Univ. degli Studi di Pavia (Italy)

771308 Absorbing photonic crystals for thin film photovoltaics [7713-07]

O. El Daif, Institut des Nanotechnologies de Lyon, Univ. de Lyon, CNRS (France), Ecole Centrale de Lyon (France), and INSA Lyon (France); E. Drouard, Institut des

Nanotechnologies de Lyon, Univ. de Lyon, CNRS (France) and Ecole Centrale de Lyon (France); G. Gomard, X. Meng, Institut des Nanotechnologies de Lyon, Univ. de Lyon, CNRS (France), Ecole Centrale de Lyon (France), and INSA Lyon (France); A. Kaminski, A. Fave, M. Lemiti, INSA Lyon (France) and Institut des Nanotechnologies de Lyon, Univ. de Lyon, CNRS (France); E. Garcia Cavrel, P. Roca i Cabarrocas, LPICM, CNRS (France) and Ecole Polyłechnique (France); S. Ahn, H. Jeon, Seoul National Univ. (Korea, Republic of);

C. Seassal, Ecole Centrale de Lyon (France) and Institut des Nanotechnologies de Lyon, Univ. de Lyon, CNRS (France) 
771309 Efficiency of thin-films silicon solar cells with a photonic pattern [7713-08]

S. Zanotto, M. Liscidini, L. C. Andreani, Univ. degli Studi di Pavia (Italy)

$7713 \mathrm{OB}$ Photonic quasi-crystal light emitting diodes: comparisons of device performance with pattern pitch [7713-10]

M. Tillin, Sharp Labs. of Europe Ltd. (United Kingdom); M. D. B. Charlton, Univ. of Southampton (United Kingdom); Z. Gong, Univ. of Strathclyde (United Kingdom);

A. Z. Khokhar, Univ. of Glasgow (United Kingdom); D. Massoubre, I. M. Watson, E. Gu,

M. D. Dawson, Univ. of Strathclyde (United Kingdom); F. Rahman, N. P. Johnson,

D. Macintyre, R. M. De La Rue, Univ. of Glasgow (United Kingdom); K. Parsons, MacDemid

Autotype Ltd. (United Kingdom); S. Lin, Luxtaltek Corp. (Taiwan)

\section{SESSION 3 CONTROLLING LIGHT IN PHOTONIC CRYSTAL MICRO- AND NANOCAVITIES}

7713 OE Activating photonic crystal membrane nanocavities by infiltrating with liquid crystals or luminescent colloidal nanocrystals [7713-13]

M. A. Dündar, C. Christova, A. Y. Silov, F. Karouta, R. Nötzel, M. Wienk, Technische Univ. Eindhoven (Netherlands); H. Salemink, Technische Univ. Delft (Netherlands);

R. W. van der Heijden, Technische Univ. Eindhoven (Netherlands)

7713 OF Coupling of cavities: the way to impose control over their modes [7713-14]

A. M. Ivinskaya, A. V. Lavrinenko, Technical Univ. of Denmark (Denmark); A. A. Sukhorukov, The Australian National Univ. (Australia); D. M. Shyroki, Max-Planck-Institut für die Physik des Lichts (Germany); S. Ha, Y. S. Kivshar, The Australian National Univ. (Australia)

\section{SESSION 4 PHOTONIC CRYSTAL-BASED INTEGRATED DEVICES}

7713 OG Ultrafast adiabatic frequency conversion using slow-light in photonic crystal waveguides (Invited Paper) [7713-15]

D. M. Beggs, Univ. of St. Andrews (United Kingdom); T. Kampfrath, L. Kuipers, FOM Institute for Atomic and Molecular Physics (Netherlands); T. F. Krauss, Univ. of St. Andrews (United Kingdom)

7713 0J A superprism-based photonic crystal demultiplexer in nearly-perfect collimation conditions [7713-18]

E. Cassan, D. Bernier, A. Lupu, X. Le Roux, D. Marris-Morini, L. Vivien, Institut d'Électronique

Fondamentale, Univ. de Paris-Sud, CNRS (France)

\section{SESSION 5 WAVE PROPAGATION IN SLOW-LIGHT PHOTONIC CRYSTAL WAVEGUIDES}

7713 OK How does slow light propagate in a real photonic-crystal waveguides? (Invited Paper) [7713-19]

S. Mazoyer, J. P. Hugonin, P. Lalanne, Lab. Charles Fabry de I'Institut d'Optique, CNRS, Univ. Paris-Sud (France); D. M. Beggs, T. F. Krauss, Univ. of St. Andrews (United Kingdom) 
$77130 \mathrm{M}$ A new kind of semi-slow light photonic crystal waveguides with large delay-bandwidth product [7713-21]

R. Hao, Univ. de Paris-Sud-11 (France) and Huazhong Univ. of Science and Technology

(China); E. Cassan, X. Le Roux, D. Marris-Morini, L. Vivien, Univ. de Paris-Sud-1 1 (France)

\section{SESSION 6 MAGNETO-PHOTONIC CRYSTALS}

7713 ON Preliminary studies of 3D magnetophotonic crystals designed from a template stuffed by sol-gel process [7713-22]

R. Kekesi, F. Royer, M. F. Blanc Mignon, Univ. de Lyon (France) and Univ. Jean Monne† Saint-Etienne (France); F. Goutaland, Univ. de Lyon (France) and Lab. Hubert Curien, CNRS, Univ. Jean Monnet Saint-Etienne (France); J. P. Chatelon, Univ. de Lyon (France) and Univ. Jean Monnet Saint-Etienne (France); E. Tombacz, Univ. of Szeged (Hungary); D. Jamon, Univ. de Lyon (France) and Univ. Jean Monnet Saint-Etienne (France)

7713 OP One-way EM waveguide formed at the interface between metal and uniformly magnetized two-dimensional photonic crystal fabricated from magneto-optic material [7713-24] S. Eyderman, V. Kuzmiak, Institute of Photonics and Electronics ASCR, v.v.i. (Czech Republic); M. Vanwolleghem, Institut d'Électronique Fondamentale, CNRS, Univ. de Paris-Sud-1 1 (France)

\section{SESSION 7 PHOTONIC EFFECTS IN DISORDERED STRUCTURES AND ANOMALOUS WAVE PROPAGATION}

7713 OS Anomalous group velocity at the high energy range of real 3D photonic nanostructures [7713-27] M. Botey, Univ. Politècnica de Catalunya (Spain); J. Martorell, ICFO-Institut de Ciències Fotòniques (Spain) and Univ. Politècnica de Catalunya (Spain); G. Lozano, H. Míguez, Instituto de Ciencia de Materiales de Sevilla (CSIC-US) (Spain); L. A. Dorado, R. A. Depine, Univ. de Buenos Aires (Argentina)

7713 OT Superluminal reflected pulses in microstrip slabs and photonic crystals [7713-28] J. Arias, A. Sánchez-Meroño, M. M. Sánchez-López, E. Ávila-Navarro, I. Moreno, Univ. Miguel Hernández de Elche (Spain)

\section{SESSION 8 APPLICATIONS OF PHOTONIC CRYSTALS TO BIOSENSING AND PHOTODETECTION}

7713 OU Porous-silicon-based photonic crystals for sensing applications (Invited Paper) [7713-29] C. Jamois, C. Li, E. Gerelli, Institut des Nanotechnologies de Lyon, CNRS, INSA-Lyon, Univ. de Lyon (France); Y. Chevolot, V. Monnier, Institut des Nanotechnologies de Lyon, CNRS, Ecole Centrale de Lyon, Univ. de Lyon (France); R. Skryshevskyi, R. Orobtchouk, Institut des Nanotechnologies de Lyon, CNRS, INSA-Lyon, Univ. de Lyon (France); E. Souteyrand, Institut des Nanotechnologies de Lyon, CNRS, Ecole Centrale de Lyon, Univ. de Lyon (France); T. Benyattou, Institut des Nanotechnologies de Lyon, CNRS, INSA-Lyon, Univ. de Lyon (France) 
7713 OV Stimuli-responsive Bragg stacks for chemo-optical sensing applications [7713-30]

B. V. Lotsch, Ludwig-Maximilians-Univ. München (Germany); F. Scotognella, Univ. degli Studi di Milano-Bicocca (Italy); K. Moeller, T. Bein, Ludwig-Maximilians-Univ. München (Germany);

G. A. Ozin, Univ. of Toronto (Canada)

7713 OX GaSb-based photonic crystal coupled cavity lasers above 2.3 um [7713-32]

S. Moumdji, LAAS, CNRS, Univ. Toulouse (France) and Univ. Montpellier 2, CNRS (France);

A. Larrue, D. Belharet, P. Dubreuil, S. Bonnefont, O. Gauthier-Lafaye, LAAS, CNRS, Univ.

Toulouse (France); Y. Rouillard, A. Vicet, Univ. Montpellier 2, CNRS (France)

\section{SESSION 9 LIGHT PROPAGATION AND DYNAMICS IN PHOTONIC/PLASMONIC STRUCTURES}

$77130 Z$ Simulations of nano-antennas with the discontinuous Galerkin time-domain method (Invited Paper) [7713-34]

J. Niegemann, M. König, K. Busch, Karlsruhe Institute of Technology (Germany)

771311 Tailored transmission in gold-coated colloidal photonic crystals [7713-36]

B. Ding, M. E. Pemble, M. Bardosova, Tyndall National Institute, Univ. College Cork (Ireland):

A. V. Korovin, U. Peschel, Friedrich-Alexander-Univ. Erlangen-Nürnberg (Germany);

S. G. Romanov, Friedrich-Alexander-Univ. Erlangen-Nürnberg (Germany) and loffe Physical Technical Institute (Russian Federation)

771312 Femtosecond dynamics of resonantly enhanced surface plasmons in planar plasmonic crystals [7713-37]

P. P. Vabishchevich, F. Y. Sychev, V. O. Bessonov, M. R. Shcherbakov, T. V. Dolgova, Lomonosov Moscow State Univ. (Russian Federation); E. D. Mishina, A. S. Sigov, Moscow State Institute of Radiotechnics, Electronics and Automation (Russian Federation);

A. A. Fedyanin, Lomonosov Moscow State Univ. (Russian Federation)

\section{SESSION 10 NONLINEAR EFFECTS IN PHOTONIC CRYSTALS}

771315 Broadband phase-matched second-harmonic generation for narrow beams in planar two-dimensional photonic crystals [7713-40]

C. Nistor, C. Cojocaru, J. Trull, Univ. Politècnica de Catalunya (Spain); K. Staliunas, Univ. Politècnica de Catalunya (Spain) and ICREA Barcelona (Spain)

771316 Fabrication of GaN/AIGaN 1D photonic crystals designed for nonlinear optical applications [7713-41]

T. Stomeo, G. Epifani, V. Tasco, A. Massaro, I. Tarantini, A. Campa, M. De Vittorio,

A. Passaseo, National Nanotechnology Lab. (Italy); M. Braccini, M. C. Larciprete, C. Sibilia, Univ. degli Studi di Roma La Sapienza (Italy); F. A. Bovino, Elsag Datamat S.p.A. (Italy)

SESSION 11 NOVEL MATERIALS AND TECHNIQUES FOR PHOTONIC CRYSTAL FABRICATION

771318 Flexible and transferable one-dimensional photonic crystals based on polymer infiltrated nanoparticle multilayers [7713-43]

M. E. Calvo, H. Míguez, Instituto de Ciencia de Materiales de Sevilla (CSIC-US) (Spain) 
7713 1D Photonic membranes and photonic crystal resonators for all-optical signal processing [7713-48]

E. Y. Glushko, V. Lashkaryov Institute of Semiconductor Physics (Ukraine); O. Glushko, V. Lashkaryov Institute of Semiconductor Physics (Ukraine) and Univ. of Leoben (Austria);

L. A. Karachevtseva, V. Lashkaryov Institute of Semiconductor Physics (Ukraine)

7713 IE Optical dispersion filters with gain [7713-49]

R. Günster, Univ. der Bundeswehr München (Germany)

$77131 \mathrm{H}$ All-nanoparticle-based optical resonators for detection of gases and liquids [7713-52] O. Sánchez-Sobrado, M. E. Calvo, N. Núñez, M. Ocaña, G. Lozano, H. Míguez, Instituto de Ciencia de Materiales de Sevilla (CSIC-US) (Spain)

771311 Mesostructured thin films as photonic crystal building blocks for sensing applications [7713-53]

N. Hidalgo, M. E. Calvo, H. R. Mìguez, Instituto de Ciencia de Materiales de Sevilla, (CSIC-US) (Spain)

7713 1J Fabrication of three-dimensional metallodielectric photonic crystals by interference lithography [7713-54]

P. N. Dyachenko, S. V. Karpeev, Image Processing Systems Institute (Russian Federation) and Samara State Aerospace Univ. (Russian Federation); E. V. Fesik, Samara State Aerospace Univ. (Russian Federation); Y. V. Miklyaev, South-Ural State Univ. (Russian Federation); V. S. Pavelyev, Image Processing Systems Institute (Russian Federation) and Samara State Aerospace Univ. (Russian Federation); G. D. Malchikov, Samara State Aerospace Univ. (Russian Federation)

$77131 \mathrm{~L} \quad$ Novel polarization beam splitters based on simple dielectric periodic structure [7713-56] Y. Zhang, W. Xue, Y. Jiang, Beijing Institute of Technology (China)

$77131 \mathrm{M} \quad$ All-optical switching in photonic crystals based on porous silicon [7713-57] S. M. Afonina, E. D. Maslennikov, S. V. Zabotnov, L. A. Golovan, Lomonosov Moscow State Univ. (Russian Federation)

7713 iN Photonic crystal microcavity in GaN-on-sapphire slab waveguide for sensor applications [7713-58]

S. Lis, Wroclaw Univ. of Technology (Poland); R. Dylewicz, Univ. of Glasgow (United Kingdom); K. Ptasiński, S. Patela, Wroclaw Univ. of Technology (Poland)

7713 1P Band-pass filters based on the omnidirectional reflection of one-dimensional photonic crystals [7713-60]

S. Li, Tibet Institute for Nationalities (China); B. Chen, Xi'an Jiaotong Univ. (China); X. Gao, Xianyang Pianzhuan Group Corp. (China)

7713 1Q GaN/AIGaN microcavities for enhancement of nonlinear optical effects [7713-61] V. Tasco, I. Tarantini, A. Campa, A. Massaro, T. Stomeo, G. Epifani, A. Passaseo, National Nanotechnology Lab., CNR-INFM, Univ. del Salento (Italy); M. Braccini, M. C. Larciprete, C. Sibilia, Univ. degli Studi di Roma La Sapienza (Italy); F. A. Bovino, Elsag Datamat S.p.A. (ltaly) 
7713 is Subwavelength structures for infrared filtering [7713-63]

S. Kurth, Fraunhofer-Institut für Einrichtung Elektronische Nanosysteme (Germany); K. Hiller, Technische Univ. Chemnitz (Germany); N. Neumann, InfraTec GmbH (Germany); M. Seifert, Technische Univ. Chemnitz (Germany); M. Ebermann, InfraTec GmbH (Germany); J. Zajadacz, Leibniz-Institut für Oberflächenmodifizierung e.V. (Germany); T. Gessner, Fraunhofer-Institut für Einrichtung Elektronische Nanosysteme (Germany)

7713 iT Optical bistable switching with Kerr nonlinear materials exhibiting a finite response time in two-dimensional photonic crystals [7713-64]

A. Naqavi, Ecole Polytechnique Fédérale de Lausanne (Switzerland); Z. MonemHaghdoost, Sharif Univ. of Technology (Iran, Islamic Republic of); H. Abediasl, GLSE Institute of Technology (United States); S. Khorasani, K. Mehrany, Sharif Univ. of Technology (Iran, Islamic Republic of)

7713 IW Low index-contrast aperiodically ordered photonic quasicrystals for the development of isotropic photonic band-gap devices (Best Student Paper Award) [7713-67]

T. Priya Rose, E. Di Gennaro, A. Andreone, G. Abbate, CNR-SPIN, Univ. degli Studi di Napoli Federico II (Italy)

7713 1X Analysis of nonlinear optical properties of photonic crystal beam splitters [7713-68] R. K. Ramakrishnan, Indian Institute of Science (India); S. Warrier, Indian Institute of Science (India) and Univ. Gent (Belgium); P. Angadikkunnath, A. Shenoy, S. Talabatulla, Indian Institute of Science (India)

7713 IY Nanometre control and determination of hole size in photonic crystal slabs [7713-69] D. M. Beggs, L. O'Faolain, T. F. Krauss, Univ. of St. Andrews (United Kingdom)

771312 Design, modeling and optimization of gallium nitride-based photonic crystal structures [7713-70]

K. Ptasínski, S. Lis, M. Wielichowski, S. Patela, Wroclaw Univ. of Technology (Poland)

771320 Design, fabrication, and optical characterization of Fabry-Pérot tunable resonator based on microstructured Si and liquid crystal [7713-71]

V. A. Tolmachev, loffe Physico-Technical Institute (Russian Federation) and Trinity College Dublin (Ireland); V. A. Melnikov, A. V. Baldycheva, T. S. Perova, Trinity College Dublin (Ireland); G. I. Fedulova, loffe Physico-Technical Institute (Russian Federation)

771321 Design of three-component one-dimensional photonic crystals for alteration of optical contrast and omni-directional reflection [7713-72]

A. V. Baldycheva, Trinity College Dublin (Ireland); V. A. Tolmachev, Ioffe Physico-Technical Institute (Russian Federation); T. S. Perova, Trinity College Dublin (Ireland); K. Berwick, Dublin Institute of Technology (Ireland)

Author Index 


\title{
Conference Committee
}

\author{
Symposium Chairs
}

Francis Berghmans, Vrije Universiteit Brussel (Belgium)

Ronan Burgess, European Commission (Belgium)

Jürgen Popp, Institut für Photonische Technologien e.V. (Germany)

Peter Hartmann, SCHOTT AG (Germany)

Hugo Thienpont, Vrije Universiteit Brussel (Belgium)

Conference Chairs

Hernán R. Míguez, Instituto de Ciencia de Materiales de Sevilla (CSIC-US) (Spain)

Sergei G. Romanov, Friedrich-Alexander-Universität Erlangen-Nürnberg (Germany)

Lucio Claudio Andreani, Università degli Studi di Pavia (Italy)

Christian Seassal, Ecole Centrale de Lyon (France)

Program Committee

Wim Bogaerts, Universiteit Gent (Belgium)

Emmanuel Centeno, Université Montpellier 2 (France)

Claudio Conti, Università degli Studi di Roma La Sapienza (Italy)

Richard M. De La Rue, University of Glasgow (United Kingdom)

Rene M. De Ridder, Universiteit Twente (Netherlands)

Stefan Enoch, Institut Fresnel (France)

Alfred W. B. Forchel, Julius-Maximilians-Universität Würzburg (Germany)

Romuald Houdré, Ecole Polytechnique Fédérale de Lausanne

(Switzerland)

Jørn Marcher Hvam, Danmarks Tekniske Universitet (Denmark)

Thomas F. Krauss, University of St. Andrews (United Kingdom)

Juan Ariel Levenson, Centre National de la Recherche Scientifique (France)

Ceferino López, Consejo Superior de Investigaciones Científicas (Spain)

Jordi Martorell, Institut de Ciències Fotòniques (Spain)

Michele Midrio, Università degli Studi di Udine (Italy)

Adriana Passaseo, National Nanotechnology Laboratory (Italy)

Min Qiu, Kungliga Tekniska Högskolan (Sweden)

Alexei Tchelnokov, CEA-LETI (France)

Pierre Viktorovitch, Ecole Centrale de Lyon (France)

Georg von Freymann, Forschungszentrum Karlsruhe GmbH (Germany)

David $\mathbf{M}$. Whittaker, The University of Sheffield (United Kingdom)

Ulrike Woggon, Technische Universität Dortmund (Germany) 
Session Chairs

1 Recent Advances in the Preparation and Characterisatoin of Self-Assembled Photonic Crystals

Hernán R. Míguez, Instituto de Ciencia de Materiales de Sevilla (CSIC-US) (Spain)

Lucio Claudio Andreani, Università degli Studi di Pavia (Italy)

2 Light Managing in Photovoltaic and Light-Emitting Devices Using

Photonic Crystals

Mikhail F. Limonov, loffe Physico-Technical Institute (Russian Federation)

3 Controlling Light in Photonic Crystal Micro- and Nanocavities Lucio Claudio Andreani, Università degli Studi di Pavia (Italy) Christian Seassal, Ecole Centrale de Lyon (France)

$4 \quad$ Photonic Crystal-based Integrated Devices

Eiichi Kuramochi, NTT Basic Research Laboratories (Japan)

5 Wave Propagation in Slow-light Photonic Crystal Waveguides

Daryl M. Beggs, University of St. Andrews (United Kingdom)

6 Magneto-photonic Crystals

Eric Cassan, Institut d'Électronique Fondamentale (France)

Philippe Lalanne, Laboratoire Charles Fabry (France)

$7 \quad$ Photonic Effects in Disordered Structures and Anomalous Wave Propagation

Hernán R. Míguez, Instituto de Ciencia de Materiales de Sevilla (CSIC-US) (Spain)

Sergei G. Romanov, Friedrich-Alexander-Universität Erlangen-Nürnberg (Germany)

8 Applications of Photonic Crystals to Biosensing and Photodetection

Hernán R. Míguez, Instituto de Ciencia de Materiales de Sevilla (CSIC-US) (Spain)

$9 \quad$ Light Propagation and Dynamics in Photonic/Plasmonic Structures

Sergei G. Romanov, Friedrich-Alexander-Universität Erlangen-Nürnberg (Germany)

Christian Seassal, Ecole Centrale de Lyon (France)

10 Nonlinear Effects in Photonic Crystals

Kurt Busch, Universität Karlsruhe (Germany) 
11 Novel Materials and Techniques for Photonic Crystal Fabrication Bettina V. Lotsch, Ludwig-Maximilians-Universität München (Germany)

Downloaded From: https://www.spiedigitallibrary.org/conference-proceedings-of-spie on 26 Apr 2023 Terms of Use: https://www.spiedigitallibrary.org/terms-of-use 
Downloaded From: https://www.spiedigitallibrary.org/conference-proceedings-of-spie on 26 Apr 2023

Terms of Use: https://www.spiedigitallibrary.org/terms-of-use 


\section{Introduction}

Since its blooming in the late eighties, research on photonic crystals has grown steadily to become a settled field in which scientists from very diverse areas participate actively. This interdisciplinary atmosphere could be experienced during the 2010 edition of the Photonic Crystal Materials and Devices conference held in Brussels, in which physicists, chemists, and engineers met to share and debate about their latest results. As it has been the case in previous editions of the conference, an adequate balance between works focused on the theoretical description of materials and devices and their actual realization and characterization was achieved. Among the wide diversity of topics covered by the different contributors, several works belonging to well-established research areas within the field could be identified, such as self-assembled photonic crystals or light propagation in photonic crystal waveguides. However, some of the new subjects introduced in the call for the first time attracted a good number of works as well as the attention of numerous participants in this Photonics Europe event, as it could be seen during the presentations. New growing research areas such as photonic crystals for photovoltaic or sensing applications, or the analysis of the effect of disorder on light propagation in photonic crystal materials or devices, have become high impact ones within the field and will find certainly their room in future editions of the conference.

\section{Novel perspectives of photonic crystal materials}

Recent advances in both already widespread as well as novel methods for the preparation of photonic crystals were highlighted in the conference. For instance, the growing interest and dissemination of the application of twophoton absorption-based laser scribing techniques to the field was illustrated by the work of the Foundation for Research and Technology (Greece). The introduction of well known dyes, such as Rhodamines, in the novel form of solid films in photonic crystals for sensing applications, as developed in the Institute of Materials Science of Seville, is also an example of the introduction of new synthetic routes of great potential.

The maturity of the field of self-assembled photonic crystals made out of colloidal particles was also highlighted by a number of presentations, many of them focused on the analysis of complex anomalous optical behavior, like the invited talk presented by Mikhail Limonov on the observation of Fano resonances. Although still far from applications, self-assembled photonic crystals continue to provide a platform for fundamental research on subjects such as non-linear effects, slow light enhancement of emission, or amplified optical absorption in periodic structures.

The opportunities offered by the command over the type of disorder present in colloidal based structures in terms of the control over the photon propagation was revealed by Diederik Wiersma in his talk about Levy flight of photons. From a totally different perspective, the importance of taking into account disorder and imperfections in the description of wave propagation in 
photonic crystal waveguides was evidenced by a couple of invited presentations by Philippe Lalanne and Alfredo De Rossi, which generated an exciting and lively debate. Besides disorder effects, the very precise control of light propagation in photonic crystal slab waveguides and of light-matter interaction in nanocavities was also emphasized in several presentations, especially in the talk by Eiichi Kuramochi from NTT-Tokyo on dynamically tuned photonic crystal cavities.

\section{Prospective applications}

In terms of applications, the conference covered the exciting subject of novel biological and chemical sensing devices based on multifunctional photonic crystal structures, a field that could only evolve due to the convergence of scientists of very different areas of expertise. As confirmed by the exciting presentations on one- and two-dimensional photonic crystal based sensing devices given by Cecile Jamois and Bettina Lotsch, its potential is enormous and still to be fully explored. Along with the high sensitivity and versatility that can be achieved, the relevance of controlling the physico-chemical properties of the internal photonic crystal surfaces in order to endow it with a selective response to the desired environmental changes or to the presence of a specific analyte became evident during the discussions, the interdisciplinary character of this research being highlighted even more.

We should also remark the great interest generated by the latest results on the application of photonic crystals to photovoltaics, be them experimental or theoretical and focused on the design and optimization. The possibility photonic crystals offer to improve the solar-to-electric power conversion efficiency by enhancing optical absorption through phenomena of light localization, slow propagation or optimum coupling to the cell structure, certainly generates great expectation. Current state of the art allows one foreseeing that new exciting results will be achieved in the next years.

Light emitting devices also deserved a great deal of interest during the conference, with relevant examples of amplification effects being shown on the luminescence from active materials, such as, for instance, erbium embedded in silicon photonic crystals. The enhancement effect on processes such as Raman scattering was also discussed. Novel passive optical elements, in which the highly anisotropic character of light propagation in photonic crystals can be put into practice, were also present in the conference.

In summary, the 2010 edition of the Photonic Crystal Materials and Devices conference (7713) provided an exciting and lively environment for scientific discussion and collaboration. The quality of the works presented, the interest generated in the participants, and the presence of many young researchers from a wide range of countries lead us to confirm the good health of the field and ensures its continuity.

\section{Hernán R. Míguez Sergei G. Romanov Lucio Claudio Andreani Christian Seassal}

